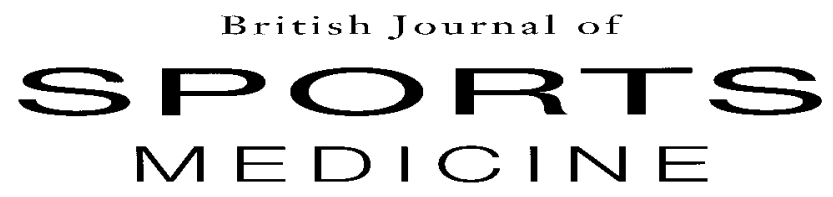

\title{
Editorials
}

Warm up

Over the moon! Training in space. Planned physical activity should be the optimal way to maintain muscle function and prevent the detraining effect of weightlessness, but it's not. The body was designed to resist gravity and staying for long periods in space creates considerable adaptive problems ( $p$ 154). Sport and space travel; a cliché comes of age. Sport is full of clichés and boxing seems to attract more than its share. Nothing like a good fight or a good argument to bring them out. There seems little argument, however, about the safety of boxing. It is inherently dangerous and medical involvement seems incompatible with the duties of the caring profession. But, George O'Neill highlights the moral and social issues and endorses the role of doctors ( $p$ 153). His arguments are persuasive and intellectually challenging. He pulls no punches.

Level playing fields are rare in sport. Especially if you are an endurance athlete seeking every fair advantage. The science of altitude training has developed greatly and athletes, together with the physiologists, appear to have overcome many of the adaptive and training difficulties. Living high and training low offers the best of both worlds ( $p$ 150). Level playing fields will, however, be a major feature of one of the major sporting events of the English summer when the 1999 Cricket World Cup finals are played at Lords on 20 June. If England have a successful campaign it will be partly attributable to the influence of sports doctors on training and coaching through bowling guidelines and modification of technique ( $\mathrm{p}$ 151). Sports physicians have a different role in disabled sport and doctors who originally promoted exercise in rehabilitation now find themselves as policemen ( $\mathrm{p}$ 152). Cheating through misclassification. It's just not cricket!

We also publish a whole menagerie of various original papers from cycling ( $p$ 178) to karate ( $p$ 174), from resistance training ( $p$ 190) to football (p 196), saliva ( $p$ 204), mouthguards ( $\mathrm{p}$ 186), and horse riding ( $\mathrm{p} 212$ ). Sorry, no parrots. The most common presentation in sports medicine. Sick as a parrot.

\section{Science or show business}

Dim the lights, cue the slides, wait for the star. The sports medicine guru is here to dispense wisdom, complete with action photographs, athletes' endorsements, and years of experience. But, how much of this wisdom is fact, how valid is experience, and dare we question the maestro's gospel?

Researchers in sport and exercise medicine have begun to question the evidence for some common practices and search for the science behind screening. We may question even the basic principles of musculoskeletal examination. ${ }^{1}$ In the past, clinicians accepted the established clinical signs without question, but arthroscopic examination began to highlight inaccuracies in established clinical tests, such as McMurrays and Apleys. Generations of students had accepted the wisdom of "experts" without well designed studies. The positive predictive value was verified anecdotally by surgery, but there was no surgical intervention in those in whom the test was negative, so we did not know. We can now evaluate the accuracy of most clinical orthopaedic examination techniques and determine their sensitivity, specificity, positive and negative predictive value using magnetic resonance imaging.

The pre-participation medical examination has become an accepted part of clinical practice, with established guidelines and procedures. ${ }^{2}$ Although it is essentially a screening procedure, it does not meet the recognised criteria for use in screening. ${ }^{3}$ The main purposes of this examination are to gather baseline data for future reference, to detect manageable medical conditions that may interfere with taking part in sports, to determine whether there are contraindications to participation, and to discover predisposition to injury, including previous athletic injuries that require rehabilitation before further participation. Depending on the population being screened there may be additional features. There is little evidence, however, that such screening is effective. In a study in the United States, of 10540 pre-season examinations in athletes aged 10-19 years over a five year period, the rate of detection of abnormality was exceptionally low and the nature of these abnormalities appeared minor. ${ }^{4}$ If recommended rates of remuneration for doctors in the United Kingdom are used, the cost would have been almost $£ 600000$ to detect 47 abnormalities of questionable value. In a compilation of four other studies, with a total of 7358 examinations, an abnormality was detected in 0.2 to $1.3 \%$.

Perhaps if we could detect muscle imbalance predisposing to injury we could use the pre-participation medical as a tool in prevention. Based on this empirical logic, isokinetic muscle dynamometry has become an integral part of pre-participation examinations. This is not 
supported, however, by a recent methodologically sound cohort study of Australian Rules footballers. ${ }^{5}$ In this study a $10 \%$ imbalance of hamstring strength between sides, or a hamstring to quadriceps ratio of less than $60 \%$ on either leg did not increase the risk of injury. The authors concluded that isokinetic strength testing was unable to discriminate between injured and non-injured players or predict the likelihood of injury. Its role as a pre-season screening tool to identify footballers at risk of injury may be limited.

Media pressure can also influence clinical practice. There are few events more tragic than the sudden death of a young person, yet one in 10 sudden deaths in young people is associated with sport. In a study of 158 sport related deaths in the young the most common cause of death was hypertrophic obstructive cardiomyopathy (HCM). ${ }^{6}$ One could argue that a pre-participation medical examination might have prevented these events but of the 158 deaths in this study, 115 had had a standard pre-participation medical examination. Only four were suspected of having cardiovascular disease and in only one case was the lesion correctly identified. It is also important to ask if it is reasonable to exclude a young athlete with HCM from participation in sport and, if so, who should make this exclusion. For many conditions we do not have sufficient evidence from longitudinal studies that exclusion will change outcome. A recent study of 14 patients with HCM has shown that it is possible to undertake intensive training, and 12 of the 14 competed at the elite level. ${ }^{7}$ Similarly, the major cause of death during sport for adults is ischaemic heart disease, but a review of studies of screening programmes for the disease suggests that they are expensive and ineffective. ${ }^{8}$ The exercise stress test is insufficiently sensitive to detect those at risk and has an unacceptably high false positive rate.
Even in our guidelines for the basic treatment of soft tissue injury with ice ${ }^{9}$ and compression ${ }^{10}$ we lack sound evidence. To establish ourselves as a valid discipline we must be prepared to subject our clinical practice to close examination. The travelling expert must provide quality research evidence and not just pretty pictures. Paul McCrory summarised it eloquently when he pointed out recently that the plural of anecdote is not data. ${ }^{11}$ If this piece had been entitled "evidence based medicine" you might not have read it, but evidence is what we need. Until we can provide science to underpin clinical practice, we are just pulling rabbits out of a hat.

DOMHNALL MACAULEY

1 Grindell S. Evidence based medicine in the musculoskeletal examination. $\mathrm{Br}$ f Sports Med 1998;32:278-9.

2 Cantwell J. Why do a pre-participation medical. Med Sci Sports Exerc 1998; 30:S341-4.

3 Wilson J, Jungner G. Principles and practice of screening for disease. Geneva: World Health Organisation, 1968.

4 Magnes SAQ, Henderson JM, Hunter SC. What conditions limit sport participation? Experience with 10,540 athletes. Phys Sports Med 1992;20:14359 .

5 Bennell $\mathrm{K}$, Wajswelner $\mathrm{H}$, Lew $\mathrm{P}$, et al. Isokinetic strength testing does not predict hamstring injury in Australian Rules footballers. Br $\mathcal{F}$ Sports Med 1998;32:309-14.

6 Maron BJ, Shirani J, Poliac LC, et al. Sudden death in young competitive athletes. $\mathcal{F} A M A$ 1996;276:199-200.

7 Maron BJ, Klues HG. Surviving competitive athletes with hypertrophic cardiomyopathy. Am f Cardiol 1994;73:1098-104.

8 Thompson PD. The cardiovascular complications of vigorous physical activity. Arch Intern Med 1996;156:2297-302.

9 Kerr KM. Guidelines for the management of soft tissue (musculoskeletal) injury with protection, rice, ice, compression, and elevation (PRICE) during the first 72 hours [abstract]. Br f Sports Med 1998;32:89.

10 Wilson S, Cooke M. Double bandaging of sprained ankles. BMF 1998;317: 1722-3.

11 McCrory P. The eighth wonder of the world: the mythology of concussion management. Br f Sports Med 1999;33:136-7. 


\section{Editor's audit report for 1998}

During 1998 we received 244 manuscripts - an increase of $36 \%$ on 1997 . This included original papers, reviews, short reports, and letters (table 1). Manuscripts came from all over the world, though predominantly from the United Kingdom and North America (table 2). During the year we published 68 original articles. Of unsolicited manuscripts this represents an acceptance rate of $36 \%$. The increase in volume has been matched by the quality of manuscripts, and our reviewers have remarked upon a considerable improvement in submissions. This has made decisions on acceptance or rejection much more difficult. Authors who have had papers published in the past have commented on the higher standards now required. In response to the increased numbers of quality submissions we increased the number of issues to six a year and the journal is now published bimonthly. One of our most successful initiatives has been the commitment to publish abstracts of the scientific meeting of the British Association of Sport and Medicine. In recent years the number of submitted abstracts has increased so that this is now considered to be one of the most successful parts of the annual congress.

Authors are very important and we work hard to meet their needs. For an author there are two key factors- the time to decision and the time to publication. In 1998 the mean time until receipt of our reviewers' opinions and editor's decision was 56 days. For some of our more specialised papers it can take a little longer but we can, occasionally, have a decision within 14 days. We aim to have no backlog so that if your paper is accepted it should be published in one of the next two issues of the journal. Depending on the time of the year this may take 3-5 months. It is theoretically possible, however, to have a manuscript submitted, reviewed, accepted, and published within 12 weeks. Book reviews are usually published as soon as they become available but may be held over if space is limited. Fillers are published when space permits. Authorship can be a difficult issue and we now offer the

\begin{tabular}{lr} 
Table 1 & Articles submitted by category \\
\hline Category & No \\
\hline Original papers & 101 \\
Case reports & 24 \\
Short reports & 42 \\
Leading articles & 22 \\
Reviews & 13 \\
Letters & 16 \\
Occasional pieces & 6 \\
Fillers & 18 \\
Clinical tests & 1 \\
Course review & 1 \\
Total & 244 \\
\hline
\end{tabular}

Table 2 Geographical distribution of submissions

\begin{tabular}{lr}
\hline Area & No \\
\hline United Kingdom & 139 \\
Western Europe & \\
Austria & 3 \\
Eire & 4 \\
France & 6 \\
Greece & 1 \\
Holland & 3 \\
Israel & 2 \\
Italy & 2 \\
Portugal & 1 \\
Spain & 6 \\
Turkey & 4 \\
USA and Canada & 28 \\
Japan & 3 \\
Australasia & 13 \\
Scandinavia & 9 \\
Asia & 7 \\
Africa & 2 \\
\hline
\end{tabular}

option of contributorship so that everyone who has helped with the paper may be recognised for their work.

Readers should have noticed some changes in the presentation of articles. We have increased the number of commentaries to allow our readers to put a particular study in the context of current literature. We ask all our authors to provide "Take home messages" and we have increased the number of summary boxes.

The increase in journal activity has had a major impact on the workload of everyone involved with the journal. For every new paper we have at least two reviews, often re-reviews, commission a commentary, and must coordinate every stage of the process. A $36 \%$ increase in throughput has generated a huge increase in work at the London office. Our authors, reviewers, editorial board, and the editor all know that this would not have been possible without the tremendous commitment of our editorial assistant, Mavis Burrell, who masterminds the entire journal. Our reviewers have also worked hard throughout the year and the editorial board have been busy and made many suggestions. The journal made the news on many occasions during the year, thanks entirely due to Caroline White, who coordinates our media relations and had many successes. Professor Ron Maughan the associate editor has, as always, been a great help and provided valuable advice. Valerie Crean, from BMJ Specialist Journals, has been a wonderful resource and with the invaluable help of Chris Wakefield ensures that the journal all comes together at the right time. The success of the journal is however due to you, our readers and authors. Your interest, enthusiasm, and academic endeavour are what make the journal. The success of our journal is your success. 